\title{
MAFLD AND NAFLD: is there the need for redefining the risk of cardiovascular disease and mortality?
}

\author{
Rosa Lombardi ${ }^{1,2}$, Annalisa Cespiati ${ }^{1,2}$, Paolo Francione ${ }^{1,2}$, Felice Cinque ${ }^{1,2}$, Silvia Fargion ${ }^{2}$, Anna Ludovica \\ Fracanzani $^{1,2}$ \\ 'Unit of Internal Medicine and Metabolic Disease, Fondazione Ca' Granda IRCCS Ospedale Maggiore Policlinico of Milan, Milan \\ 20122, Italy. \\ ${ }^{2}$ Department of Pathophysiology and Transplantation, University of Milan, Milan 20122, Italy.
}

Correspondence to: Dr. Rosa Lombardi, Unit of Internal Medicine and Metabolic Disease, Fondazione Ca' Granda IRCCS

Ospedale Maggiore Policlinico of Milan, Milan 20122, Italy. E-mail: rosa.lombardi@unimi.it

How to cite this article: Lombardi R, Cespiati A, Francione P, Cinque F, Fargion S, Fracanzani AL. MAFLD AND NAFLD: is there the need for redefining the risk of cardiovascular disease and mortality? Metab Target Organ Damage 2022;2:12.

https://dx.doi.org/10.20517/mtod.2021.13

Received: 28 Sep 2021 First Decision: 19 Nov 2021 Revised: 25 Nov 2021 Accepted: 2 Dec 2021 Published: 7 Dec 2021

Academic Editor: Mariana Verdelho Machado Copy Editor: Yue-Yue Zhang Production Editor: Yue-Yue Zhang

\begin{abstract}
Nonalcoholic fatty liver disease (NAFLD) is the most common liver disease worldwide and is characterized by a high burden of metabolic alterations. It exposes patients to increased morbidity and mortality, mostly driven by cardiovascular (CV) complications. Despite its large use, the nomenclature NAFLD has some limitations, due to the exclusion of patients with hepatic fat and concomitant other liver diseases or moderate alcohol consumption possibly contributing to hepatic damage. Therefore, a new and more inclusive dvefinition of fatty liver has recently been proposed, namely metabolic associated fatty liver disease (MAFLD). It comprises patients with hepatic steatosis and associated metabolic comorbidities, without exclusion of other liver diseases. As for the nature of the new definition of MAFLD, it could be speculated that an increased risk of cardiovascular complications should be expected. Therefore, our review aims at answering the question about possible differences in cardiovascular risk and mortality in patients with NAFLD compared to MAFLD. We selected 8 studies out of 1130 by searching in the PubMed database. Data from literature seem to report an increased risk of CV events and mortality in patients affected by MAFLD compared to NAFLD, possibly due to the metabolic burden and coexistence of other liver diseases typical of MAFLD. However, further prospective studies are warranted to confirm this preliminary hypothesis.
\end{abstract}


Keywords: Hepatic steatosis, metabolic alterations, cardiovascular risk scores, cardiovascular events, cardiovascular death

\section{INTRODUCTION}

\section{From NAFLD to MAFLD: a new definition for hepatic steatosis}

Nonalcoholic fatty liver disease (NAFLD) is the most common liver disease worldwide, with the prevalence increasing up to $30 \%$ over the last years, paralleling the spread of metabolic alterations and changes in lifestyle ${ }^{[1]}$. It is defined by the presence of fat in more than $5 \%$ of hepatocytes in the absence of excessive alcohol consumption and other causes of liver disease. It encompasses a wide spectrum of hepatic diseases ranging from simple steatosis to steatohepatitis, where inflammation arises, possibly progressing to fibrosis and cirrhosis ${ }^{[2]}$.

NAFLD exposes patients to increased morbidity and mortality, mostly driven by cardiovascular (CV) complications ${ }^{[3,4]}$. Hepatic fibrosis and metabolic alterations, especially type 2 diabetes $(\mathrm{T} 2 \mathrm{DM})^{[5,6]}$, have been identified as the most unfavorable prognostic factors for both hepatic and extrahepatic NAFLD complications.

Despite NAFLD being strictly associated with metabolic alterations, its current definition, proposed nearly 35 years ago ${ }^{[7]}$, does not include patients with hepatic fat and concomitant other liver diseases or moderate alcohol consumption [Figure 1]. Indeed, these patients may be exposed to either progressive forms of hepatic disease or increased cardiovascular risk, especially if metabolic features coexist ${ }^{[8,9]}$.

Therefore, a new concept has recently emerged and in 2020 a new inclusive term able to cover this gap has been proposed, namely metabolic associated fatty liver disease (MAFLD $)^{[10]}$. As depicted in Figure 2, the diagnosis of MAFLD is based on the evidence of hepatic fat (diagnosed by histology, imaging, or blood biomarkers) along with one of these three criteria: overweight/obesity, T2DM, or evidence of metabolic dysregulation. The latter is defined by at least two criteria in patients with normal body mass index (BMI): (1) enlarged waist circumference; (2) hypertension or anti-hypertensive treatment; (3) increased triglycerides or treatment with hypolipemic drugs; (4) low high-density lipoprotein cholesterol (HDL); (5) prediabetes; (6) high Homeostatic Model Assessment of Insulin Resistance score; and (7) high-sensitivity Creactive protein $\geq 2 \mathrm{mg}^{[11]}$. In fact, lean individuals are also at risk of developing MAFLD possibly progressing to advanced liver disease ${ }^{[12]}$ and even of having an increased cardiovascular risk compared to their overweight counterparts ${ }^{[13]}$. Finally, besides embracing metabolic abnormalities, MAFLD is also comprehensive of inflammatory markers, a well-known CV risk factor ${ }^{[14]}$.

Only one study evaluated and validated the diagnostic criteria of MAFLD in a very large American population-based dataset, analyzing data from 13,083 individuals from the National Health and Nutrition Examination Surveys III (NHANES III) cohort. The results show that, despite a similar prevalence of MAFLD and NAFLD (around 30\%), MAFLD patients presented a higher burden of metabolic comorbidities, as well as higher liver enzymes and hepatic fibrosis stages, possibly suggesting that MAFLD criteria can better discriminate patients at risk ${ }^{[15]}$.

Given the metabolic hallmark of the new definition of MAFLD, as well as the possible coexistence of other liver diseases along with hepatic steatosis, it could be speculated that an increased risk of cardiovascular complications should be expected ${ }^{[16]}$. Indeed, data about CV alterations in MAFLD are limited and not conclusive, possibly because of the very recent coining of the concept of MAFLD itself. 

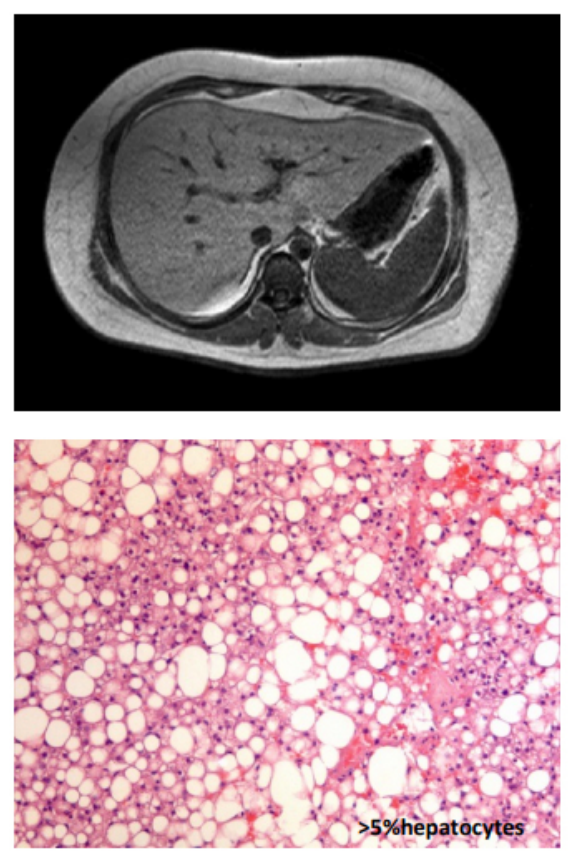

Hepatic fat

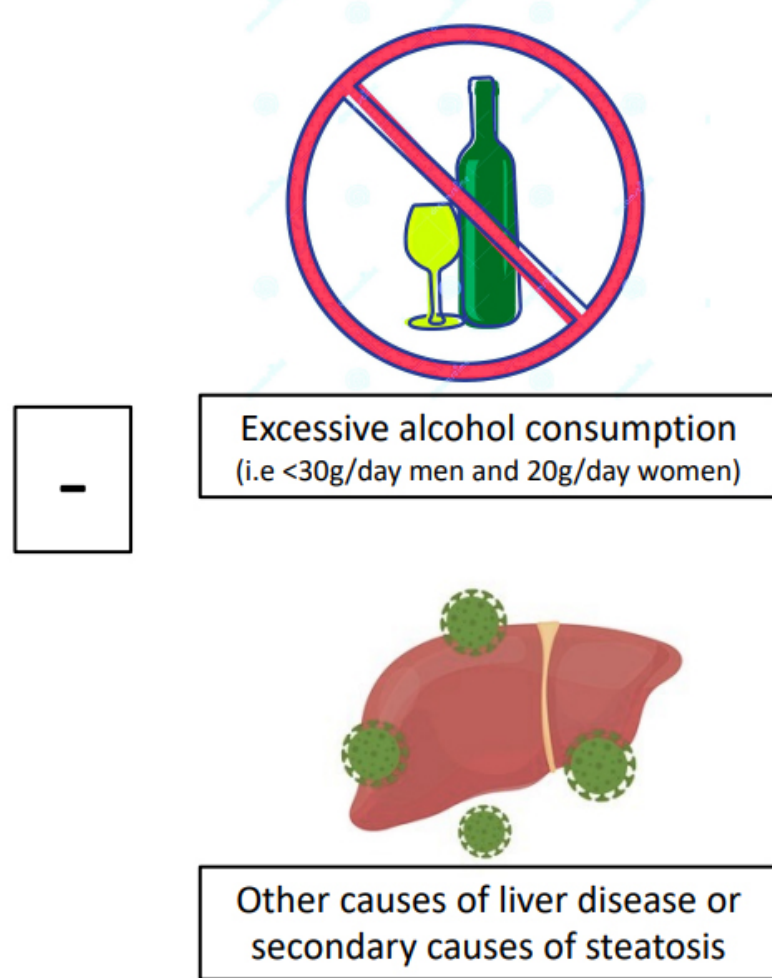

Figure 1. Definition of nonalcoholic fatty liver disease (NAFLD).

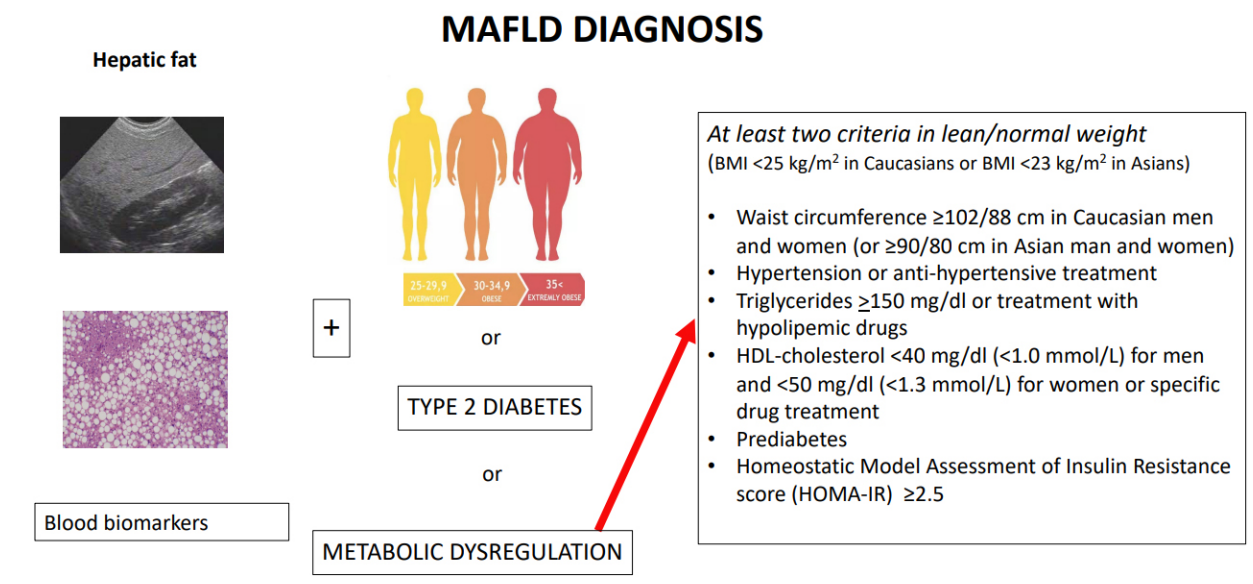

Figure 2. Definition of metabolic associated fatty liver disease (MAFLD).

Therefore, this review focuses on the difference in cardiovascular risk and mortality in patients with NAFLD compared to MAFLD. Published data for this review were identified by search and the selection of the PubMed database using the search terms "NAFLD" AND "MAFLD" combined with "cardiovascular risk", "cardiovascular disease", "cardiovascular damage”, "carotid plaques”, "atherosclerosis”, "epicardial fat", and "mortality". Relevant articles were selected, including observational, retrospective, and prospective studies. In total, 1130 studies were found. After excluding duplicates, congress abstracts, and review articles, as well as studies not reporting results on the comparison between NAFLD and MAFLD, eight studies were 
selected and included in the review.

\section{CARDIOVASCULAR DISEASE}

A high cardiovascular risk has been reported in patients with NAFLD, especially if metabolic comorbidities are present ${ }^{[17]}$, and a recent and large meta-analysis of observational studies ( $n=34,043$ adult individuals) reported a 1.63-fold increased risk of CV events ${ }^{[18]}$. In addition, NAFLD has been associated with subclinical atherosclerosis, endothelial dysfunction, myocardial remodeling, heart failure, and cardiac arrythmias ${ }^{[19-23]}$. Even though NAFLD prevalence varies according to race, with the highest presence in Hispanics and lowest in African-American individuals ${ }^{[24]}$, a multi-ethnic study including more than 6800 participants with NAFLD did not highlight an established role for race in determining an augmented risk of both clinical and subclinical CV damage, as well as of mortality ${ }^{[25-27]}$.

Given the recent change in nomenclature from NAFLD to MAFLD addressing the issue of liver steatosis, questioning on the possible changes in $\mathrm{CV}$ outcomes related to this condition is mandatory.

As a consequence, data in the literature comparing the cardiovascular risk of patients affected by NAFLD or MAFLD are emerging, however they are scarce and not conclusive [Table 1].

\section{Cardiovascular events in patients with NAFLD and MAFLD}

A prospective study by Niriella et al. ${ }^{[28]}$ enrolled a cohort of 2985 patients with ultrasound-detected (US) steatosis and compared incidence of fatal (i.e., death from myocardial infarction or stroke) and non-fatal $\mathrm{CV}$ events (myocardial event, stroke, coronary artery bypass surgery, and percutaneous transluminal coronary angiography) between NAFLD and MAFLD and a control group without steatosis after seven years of follow-up. The results show a similar prevalence of NAFLD and MAFLD (31\% and 33\%, respectively) and superimposable metabolic and anthropometric traits at baseline. The risks of having fatal/non-fatal CV events at follow-up were similar in the two groups, but significantly higher in both groups compared to controls $(\mathrm{RR}=3.7,95 \% \mathrm{CI}$ : $1.3-10.3$ for NAFLD; $\mathrm{RR}=4.2,95 \% \mathrm{CI}$ : $1.5-11.5$ for MAFLD). However, when considering subjects not included in the NAFLD definition but captured by the MAFLD one (MAFLD-only group) (2.9\%) and vice versa (NAFLD-only group) (1.3\%), patients included in the MAFLD definition presented higher risk of developing CV events compared to controls $(\mathrm{RR}=7.2$, 95\%CI: 2.4-21.5), whereas those in the NAFLD group did not (RR = 1.9, 95\%CI: 0.25-14.8). Similarly, when considering lean subjects (i.e., those with BMI $<25 \mathrm{~kg} / \mathrm{m}^{2}$ ), there was no difference in the occurrence rate of CV events in MAFLD and NAFLD subjects; however, MAFLD-only patients presented a higher ratio of CV events compared to controls, whereas NAFLD-only patients did not. The authors concluded that MAFLD definition identified more high-risk subjects compared to NAFLD. Nonetheless, the loss to follow-up in nearly $30 \%$ of the cohort may weaken this conclusion, even though Lee et al.$^{[29]}$ also confirmed this evidence. In fact, analyzing data from the Korean nationwide health information database, the authors retrieved information of more than nine million people, finding a prevalence of NAFLD and MAFLD of $28 \%$ and $37 \%$, respectively. Most importantly, cumulative incidence of fatal (death from a CV event) and non-fatal $\mathrm{CV}$ events (myocardial infarction and ischemic stroke) was higher in the MAFLD-only group compared to the NAFLD-only group. When considering a control group without steatosis as reference, the hazard ratio for CV events were 1.09 (95\%CI: 1.03-1.15) in the NAFLD-only group, 1.43 (1.41-1.45) in the MAFLD-only group, and 1.56 (1.54-1.58) in patients fulfilling criteria of both MAFLD and NAFLD. Moreover, a subgroup analysis showed that the CV events incidence rate was higher in the lean MAFLD group compared to the obese MAFLD group, confirming the highly unfavorable profile of lean subjects with hepatic steatosis ${ }^{[29]}$. In addition, the association between MAFLD and CV disease remained significant even when adjusted for or stratified by the cardiometabolic risk factors (overweight, diabetes, hypertension, and dyslipidemia) and was 
Table 1. Literature comparing the cardiovascular risk of patients affected by NAFLD or MAFLD

\begin{tabular}{|c|c|c|c|c|c|c|c|c|}
\hline Authors & Year & $\begin{array}{l}\text { Type of } \\
\text { study }\end{array}$ & Population & $\begin{array}{l}\text { Follow- } \\
\text { up }\end{array}$ & Endpoint & $\begin{array}{l}\text { Prevalence of } \\
\text { NAFLD and } \\
\text { MAFLD }\end{array}$ & Results & $\begin{array}{l}\text { Risk of } / \mathrm{a} \\
\text { CV diseas } \\
\text { of patien } \\
\text { vs. NAFL }\end{array}$ \\
\hline \multicolumn{9}{|c|}{ Cardiovascular events } \\
\hline Niriella et al. ${ }^{[28]}$ & 2021 & Longitudinal & $\begin{array}{l}2895 \text { Japanese subjects from an } \\
\text { urban population aged } 35-64 \\
\text { years }\end{array}$ & 7 years & $\begin{array}{l}\text { - Fatal CV events (i.e., } \\
\text { death from MI or stroke) } \\
\text { - Non-fatal CV events (MI, } \\
\text { stroke, CABS, } \\
\text { percutaneous transluminal } \\
\text { coronary angiography) }\end{array}$ & $\begin{array}{l}\text { 31.5\% NAFLD } \\
\text { 33.2\% MAFLD } \\
\text { 1.3\% NAFLD-only } \\
\text { 2.9\% MAFLD-only } \\
\text { (steatosis diagnosed } \\
\text { by US) }\end{array}$ & $\begin{array}{l}\text { - Risk of fatal and non-fatal CV events: } \\
\text { MAFLD group (RR }=4.2 ; 95 \% \mathrm{Cl}: 1.5- \\
\text { 11.5), NAFLD group (RR }=3.7 ; 95 \% \mathrm{Cl} \text { : } 1.3- \\
\text { 13.3) } \\
\text { - Incidence of fatal and non-fatal CV } \\
\text { events: MAFLD-only group } 14.3 \% \text { vs. } \\
\text { NAFLD-only group 3.4\% }\end{array}$ & • Higher \\
\hline Lee et al. ${ }^{[29]}$ & 2021 & Longitudinal & $\begin{array}{l}9,584,399 \text { Korean subjects from } \\
\text { the Nationwide health screening } \\
\text { database aged } 40-64 \text { years }\end{array}$ & 10 years & $\begin{array}{l}\text { Composite CV event (first } \\
\text { hospitalization for } \mathrm{Ml} \text {, } \\
\text { ischemic stroke, heart } \\
\text { failure, or CV-related } \\
\text { death) }\end{array}$ & $\begin{array}{l}28 \% \text { NAFLD } \\
37 \% \text { MAFLD } \\
0.6 \% \text { NAFLD-only } \\
9.9 \% \text { MAFLD-only } \\
27 \% \text { both } \\
\text { NAFLD/MAFLD } \\
\text { (steatosis diagnosed } \\
\text { by FLI) }\end{array}$ & $\begin{array}{l}\text { - Risk of CV events: non-steatosis group } \\
\text { (HR }=1.00) \text {, NAFLD-only group (HR = } \\
1.09 ; 95 \% \mathrm{Cl}: 1.03-1.15) \text {, MAFLD-only } \\
\text { group (HR }=1.43 ; 95 \% C l: 1.41-1.45) \\
\text { NAFLD/MAFLD group [1.56 (1.54-1.58)] }\end{array}$ & • Higher \\
\hline Guerreiro et al. ${ }^{[30]}$ & 2021 & $\begin{array}{l}\text { Retrospective } \\
\text { Cross- } \\
\text { sectional }\end{array}$ & $\begin{array}{l}1233 \text { Brazilian patients aged }>18 \\
\text { years submitted to liver biopsy at a } \\
\text { referral service of a university } \\
\text { hospital [of whom } 171 \text { (13.9\%) } \\
\text { with steatosis] }\end{array}$ & - & $\begin{array}{l}\text { Composite CV event } \\
\text { (Ischemic heart disease, } \\
\text { MI, atherosclerosis, aortic } \\
\text { valve stenosis, and stroke) }\end{array}$ & $\begin{array}{l}63.7 \% \text { NAFLD } \\
90.1 \% \text { MAFLD } \\
\text { (steatosis diagnosed } \\
\text { by histology) }\end{array}$ & $\begin{array}{l}\text { - Prevalence of CV events in MAFLD } \\
\text { group vs. NAFLD group ( } 20 \% \text { vs. } 13 \%, P= \\
0.137 \text { ) }\end{array}$ & - Similar \\
\hline Zhang et al. ${ }^{[31]}$ & 2021 & $\begin{array}{l}\text { Cross- } \\
\text { sectional }\end{array}$ & $\begin{array}{l}\text { Non-institutionalized US } \\
\text { population from the US National } \\
\text { Health and Nutrition Examination } \\
\text { Surveys (NHANESs) }\end{array}$ & - & MI, stroke & $\begin{array}{l}47.9 \% \text { to } 47.8 \% \\
\text { NAFLD } \\
47.4 \% \text { to } 48.2 \% \\
\text { MAFLD } \\
\text { (from } 1999 \text { to } 2016, \\
\text { steatosis diagnosed } \\
\text { by US-FLI) }\end{array}$ & $\begin{array}{l}\text { - Risk of MI: MAFLD group (OR = 1.79; } \\
95 \% \text { Cl: } 1.5-2.13), \text { NAFLD group }(\mathrm{OR}= \\
\text { 1.78; } 95 \% \text { Cl: } 1.5-2.11) \\
\text { - Risk of stroke: MAFLD group }(\mathrm{OR}=1.63 ; \\
95 \% \mathrm{Cl}: 1.32-2.0) \text {, NAFLD group }(\mathrm{OR}= \\
1.60 ; 95 \% \mathrm{Cl}: 1.27-2.0)\end{array}$ & - Similar \\
\hline \multicolumn{9}{|c|}{ Cardiovascular risk scores } \\
\hline Lee et al. ${ }^{[29]}$ & 2021 & Longitudinal & $\begin{array}{l}9,584,399 \text { Korean subjects from } \\
\text { the Nationwide health screening } \\
\text { database aged } 40-64 \text { years }\end{array}$ & 10 years & $\begin{array}{l}\text { Korean Risk Prediction } \\
\text { Model (KRPM) }\end{array}$ & $\begin{array}{l}28 \% \text { NAFLD } \\
37 \% \text { MAFLD } \\
0.6 \% \text { NAFLD-only } \\
9.9 \% \text { MAFLD-only } \\
27 \% \text { both } \\
\text { NAFLD/MAFLD } \\
\text { (steatosis diagnosed } \\
\text { by FLI) }\end{array}$ & $\begin{array}{l}\text { - Prevalence of KRPM > 10\%: non- } \\
\text { steatosis group (3.1\%), in NAFLD only } \\
\text { group }(2.1 \%), \text { MAFLD only group (11\%), } \\
\text { NAFLD/MAFLD group ( } 9.5 \%)\end{array}$ & • Higher \\
\hline Guerreiro et al. ${ }^{[30]}$ & 2021 & $\begin{array}{l}\text { Retrospective } \\
\text { Cross- } \\
\text { sectional }\end{array}$ & $\begin{array}{l}1233 \text { Brazilian patients aged }>18 \\
\text { years submitted to liver biopsy at a } \\
\text { referral service of a university }\end{array}$ & - & $\begin{array}{l}\text { Atherosclerotic } \\
\text { cardiovascular disease risk } \\
\text { estimator of } \mathrm{ACC} / \mathrm{AHA}\end{array}$ & $\begin{array}{l}\text { 63.7\% NAFLD } \\
90.1 \% \text { MAFLD } \\
\text { (steatosis diagnosed }\end{array}$ & $\begin{array}{l}\text { - Prevalence of high-risk class of CV } \\
\text { scores in MAFLD group vs. NAFLD group } \\
(36.4 \% \text { vs. } 25.7 \%, P=0.209)\end{array}$ & - Similar \\
\hline
\end{tabular}




\begin{tabular}{|c|c|c|c|c|c|c|c|c|}
\hline & & & $\begin{array}{l}\text { hospital [of whom } 171 \text { (13.9\%) } \\
\text { with steatosis] }\end{array}$ & & & by histology) & & \\
\hline Zhang et al. ${ }^{[31]}$ & 2021 & $\begin{array}{l}\text { Cross- } \\
\text { sectional }\end{array}$ & $\begin{array}{l}\text { Non-institutionalized US } \\
\text { population from the US National } \\
\text { Health and Nutrition Examination } \\
\text { Surveys (NHANESs) }\end{array}$ & - & $\begin{array}{l}\text { - Framingham risk score } \\
\text { (FRS) } \\
\text { - Atherosclerotic } \\
\text { cardiovascular disease risk } \\
\text { estimator of ACC/AHA }\end{array}$ & $\begin{array}{l}47.9 \% \text { to } 47.8 \% \\
\text { NAFLD } \\
47.4 \% \text { to } 48.2 \% \\
\text { MAFLD } \\
\text { (from } 1999 \text { to } 2016 \text {, } \\
\text { steatosis diagnosed } \\
\text { by US-FLI) }\end{array}$ & $\begin{array}{l}\text { - } 10 \text {-year cardiovascular risk by } \\
\text { Framingham: MAFLD group (beta 2.6, } \\
\text { 95\%Cl: } 2.2-2.9 \text { ), NAFLD group (beta 2.1, } \\
\text { 95\%Cl: } 1.8-2.5 \text { ) } \\
\text { - } 10 \text {-year risk of cardiovascular events by } \\
\text { ACC/AHA scores: MAFLD (beta 1.9, } \\
\text { 95\%Cl: } 1.5-2.2 \text { ), NAFLD (beta 1.5, } 95 \% \text { Cl: } \\
\text { 1.1-1.8) }\end{array}$ & - Higher \\
\hline Tsutsumi et al. ${ }^{[41]}$ & 2021 & Prospective & $\begin{array}{l}2306 \text { Japanese patients with } \\
\text { steatosis }\end{array}$ & 10 years & $\begin{array}{l}\text { - Worsening of the FRS } \\
\text { - Worsening of the Suita } \\
\text { score }\end{array}$ & $\begin{array}{l}63.4 \% \text { NAFLD } \\
80.7 \% \text { MAFLD } \\
\text { (steatosis diagnosed } \\
\text { by US) }\end{array}$ & $\begin{array}{l}\text { - Cumulative incidence of worsening of } \\
\text { scores in MAFLD group compared to } \\
\text { NAFLD group (Wilcoxon test } P=0.0378 \\
\text { Suita and FRS } P=0.0097 \text { ) }\end{array}$ & - Higher \\
\hline \multicolumn{9}{|l|}{ Mortality } \\
\hline Huang et al. ${ }^{[44]}$ & 2021 & Longitudinal & $\begin{array}{l}12,480 \text { non-institutionalized } \\
\text { participants from the Third } \\
\text { National Health and Nutrition } \\
\text { Examination Survey (NHANES III) }\end{array}$ & $\begin{array}{l}20-30 \\
\text { years }\end{array}$ & $\begin{array}{l}\text { - All-cause mortality } \\
\text { - CV-related mortality } \\
\text { - Neoplasm-related } \\
\text { mortality } \\
\text { - T2DM-related mortality }\end{array}$ & $\begin{array}{l}27.4 \% \text { NAFLD } \\
27.9 \% \text { MAFLD } \\
5.1 \% \text { NAFLD-only } \\
4.6 \% \text { MAFLD-only } \\
22.8 \% \text { both } \\
\text { NAFLD/MAFLD } \\
\text { (steatosis diagnosed } \\
\text { by US) }\end{array}$ & $\begin{array}{l}\text { - Risk of overall-cause mortality: MAFLD } \\
\text { group (HR }=2.07,95 \% \mathrm{Cl}: 1.86-2.29) \text {, } \\
\text { NAFLD group (HR }=1.47,95 \% \mathrm{Cl}: 1.20- \\
1.79)\end{array}$ & - Higher \\
\hline Nguyen et al. ${ }^{[45]}$ & 2021 & Longitudinal & $\begin{array}{l}2997 \text { non-institutionalized } \\
\text { participants from the Third } \\
\text { National Health and Nutrition } \\
\text { Examination Survey (NHANES III) } \\
\text { with US evidence of steatosis }\end{array}$ & 15 years & $\begin{array}{l}\text { - All-cause mortality } \\
\text { - CV-related mortality } \\
\text { - Neoplasm-related } \\
\text { mortality } \\
\text { - Other-cause mortality }\end{array}$ & $\begin{array}{l}8 \% \text { NAFLD-only } \\
17 \% \text { MAFLD-only } \\
75 \% \text { both } \\
\text { NAFLD/MAFLD } \\
\text { (steatosis diagnosed } \\
\text { by US) }\end{array}$ & $\begin{array}{l}\text { - Cumulative all-cause mortality: MAFLD- } \\
\text { only group ( } 26 \%) \text {; NAFLD + MAFLD } \\
\text { group (21.1\%); NAFLD-only group } \\
(10.6 \%)\end{array}$ & - Higher \\
\hline Semmler et al. ${ }^{[46]}$ & 2021 & Cohort study & $\begin{array}{l}4718 \text { Austrian patients aged } 40- \\
85 \text { years, enrolled during } \\
\text { colorectal cancer screening } \\
\text { program }\end{array}$ & 7.5 years & $\begin{array}{l}\text { - } 5 \text {-year survival } \\
\text { - All-cause mortality } \\
\text { - CV-related mortality } \\
\text { - Neoplasm-related } \\
\text { mortality } \\
\text { - Liver-related mortality }\end{array}$ & $\begin{array}{l}46.9 \% \text { NAFLD } \\
47.4 \% \text { MAFLD } \\
\text { (steatosis diagnosed } \\
\text { by US) }\end{array}$ & $\begin{array}{l}\text { - 5-year overall survival rate: MAFLD } \\
\text { group }(93.9 \%), \text { NAFLD group }(98.2 \%)\end{array}$ & - Similar \\
\hline
\end{tabular}

CV: Cardiovascular; MI: myocardial infarction; CABS: coronary artery bypass surgery; FLI: fatty liver index; ACC/AHA: American College of Cardiology/American Heart Association; US: ultrasound; KRPM: Korean Risk Prediction Model; T2DM: type 2 diabetes; MAFLD: metabolic associated fatty liver disease; NAFLD: nonalcoholic fatty liver disease.

independent of alcohol consumption, suggesting that liver fat per se in the context of metabolic dysregulation is associated with incident CV events. The authors then concluded that NAFLD without metabolic abnormality was associated with lower CV risk compared to MAFLD; however, the limitation of the use of a non-invasive score (fatty liver index) for the diagnosis of steatosis should be taken into account. 
In complete opposition to these statements are the results reported by Guerreiro et al. ${ }^{[30]}$ in a cohort of Brazilian patients with steatosis at histology. Out of 1233 biopsies performed, 171 subjects (14\%) presented hepatic steatosis, of whom 64\% were diagnosed with NAFLD and 90\% with MAFLD. Data were retrospectively retrieved from 2013 and 2018, and the occurrence of non-fatal CV events (i.e., ischemic heart disease, myocardial infarction, atherosclerosis, aortic valve stenosis, and stroke) was evaluated ${ }^{[30]}$. Reports of CV events did not differ between patients with NAFLD (13\%) and MAFLD (20\%), nor did the severity of histological liver damage influence the CV risk. Interestingly, if MAFLD was associated with viral hepatitis, the prevalence of CV events increased ( $31 \%$ vs. 13\% in MAFLD patients with/without viral hepatitis ( $\mathrm{B}$ and/or $\mathrm{C}, P=0.007$ ). However, the small sample size, as well as the low prevalence of steatosis found at histology, may somehow justify the lack of association between MAFLD and CV events. Similarly, another study examined data from the US National Health and Nutrition Examination Surveys (NHANES) from 1999 to 2016 to evaluate the occurrence of CV events (myocardial infarction or stroke) in patients with MAFLD and NAFLD over time ${ }^{[31]}$. The authors showed that, despite an increasing prevalence of MAFLD in the American population over time compared to that of NAFLD, the OR of myocardial infarction or stroke was similar between MAFLD and NAFLD (myocardial infarction: $\mathrm{OR}=1.79$, 95\%CI: 1.5-2.13 and OR = 1.78, 95\%CI: 1.5-2.11; stroke: $\mathrm{OR}=1.63,95 \% \mathrm{CI}: 1.32-2.0$ and $\mathrm{OR}=1.60,95 \% \mathrm{CI}: 1.27-2.0$ ). Nevertheless, a real analysis comparing patients MAFLD $v s$. NAFLD is missing, and the results are observational.

\section{Cardiovascular risk scores}

Since patients affected by NAFLD present a high incidence of CV events, preventing their occurrence remains a public health issue. For that reason, several predictive scores have been constructed based on the most known CV risk factors, such as age, high blood pressure, high cholesterol, smoking, and $\mathrm{T} 2 \mathrm{DM}^{[32]}$.

The Framingham risk score was first created in the 1990s and estimated the 10-year risk of developing coronary heart disease $(\mathrm{CHD})^{[33]}$. In 2008, it was revised to include other variables in the score such as age, total and high density cholesterol, systolic blood pressure, T2DM, and smoking ${ }^{[34]}$. In a prospective study involving more than 300 patients affected by NAFLD and followed up for 11 years, the baseline Framingham risk score was higher in NAFLD patients compared to controls, and it was the only independent risk factor significantly associated with new onset of coronary heart disease ${ }^{[35]}$. Even though it is considered the reference standard, this score has some limitations such as estimating the risk only in American subjects and only predicting CHD. Therefore, other scoring systems have been developed, such as the one proposed by the European Society of Cardiology, namely the systematic coronary risk evaluation, able to predict 10-year risk of cardiovascular death in Europe and based on age, blood pressure, and total cholesterol $^{[36]}$. Similarly, the American College of Cardiology (ACC) and the American Heart Association (AHA) proposed another risk score able to predict 10-year risk of both fatal and non-fatal cerebral and cardiac events based on age, total and HDL cholesterol, systolic blood pressure (including treated or untreated status), diabetes, and current smoking status ${ }^{[37]}$. Indeed, in a cohort of 2804 Iranian subjects, Motamed et al. ${ }^{[38]}$ demonstrated that both the ACC/AHA and the Framingham cardiovascular risk scores were significantly higher in patients with NAFLD compared to those without it.

Finally, other scores have been developed to predict the risk of CV events in specific populations, such as the Suita score or the Korean Risk Prediction Model (KRPM). The first was developed to predict the risk of a 10-year occurrence of CHD in a healthy Japanese population of more than 5000 individuals, performing even better than the Framingham score ${ }^{[39]}$. The second was built on using factors significantly associated with the incidence of fatal or non-fatal CV events in a population of more than 200,000 Korean subjects without pre-existing CV events and followed up for 12 years (age, total cholesterol, high density cholesterol, T2DM, smoking, and systolic blood pressure $)^{[00]}$. 
Depending on the score results, clinicians may decide to start or implement a drug therapy able to reduce CV risk factors (i.e., lipids or blood pressure lowering agents) or to intensify lifestyle correction (i.e., diet and physical activity aimed at weight loss or smoke cessation).

\section{Cardiovascular risk scores in NAFLD and MAFLD}

A study by Tsutsumi et al. ${ }^{[4]]}$ enrolled 2306 Japanese subjects with fatty liver diagnosed by US, of whom 80.7\% were diagnosed with MAFLD and 63.4\% with NAFLD, and divided the whole cohort into three group: NAFLD with no metabolic dysfunction (NAFLD-only), overlapping (NAFLD + MAFLD), and MAFLD with moderate alcohol consumption (MAFLD-only). The cohort was followed up over a 10-yearperiod and the risk of coronary disease was evaluated by both the Framingham and the Suita score. The endpoint was the worsening of the scores from the low-risk to the high-risk category. The results show that the cumulative incidence of worsening of the scores was significantly higher in the MAFLD group than in the NAFLD group, only MAFLD was an independent risk factor for worsening of the scores, and the risk was only minimally consequent to alcohol consumption ${ }^{[41]}$. Similarly, when the KRPM was calculated, participants with MAFLD, with or without overlapping NAFLD, presented an elevated 10-year risk score compared to the NAFLD-only group and the control group without hepatic steatosis; conversely, patients in the NAFLD-only group did not ${ }^{[29]}$. In addition, this study, which examined data from the US NHANES, highlighted that MAFLD patients had a significantly greater 10-year risk of CV events supported by the Framingham and ACC/AHA scores compared to those with NAFLD ${ }^{[31]}$. In contrast with this evidence, Guerreiro et al. ${ }^{[30]}$, in a cohort of 171 biopsy proven NAFLD, showed no difference in the ACC/AHA CV risk score between patients with NAFLD and those with MAFLD, even when considering each histology feature.

\section{MORTALITY}

As already mentioned, patients with NAFLD are exposed to a high risk of mortality, mostly driven by cardiovascular disease, hepatic complications (hepatocellular carcinoma and end stage liver disease), and extra-hepatic cancers ${ }^{[5]}$. A recent population-based study analyzed more than 10,500 Swedish patients with histologically proven steatosis compared to an age- and sex-matched control group without steatosis $(n=$ 49,900 ) and followed up over a median of 14 years. Compared to the controls, NAFLD subjects had an increased mortality (28.6 vs. 16.9/1000 person/year), and the more was the advanced the histological liver damage, the higher was the risk ${ }^{[42]}$. A recent meta-analysis comprising 14 studies with more than 49,800 patients diagnosed with NAFLD confirmed the high risk of all-cause mortality of patients with steatosis compared to those without it ( $\mathrm{HR}=1.34 ; 95 \% \mathrm{CI}: 1.17-1.54)$, independently of age, sex, follow-up duration, body mass index, diabetes, smoking, or hypertension ${ }^{[43]}$. Nevertheless, this meta-analysis did not show any association between NAFLD and mortality specifically from CV disease or cancer.

Given the new nomenclature of hepatic steatosis, the question of whether the change from NAFLD to MAFLD could affect the association between fatty liver and long-term clinical outcomes needs to be answered. In particular, whether the MAFLD term is superior to NAFLD in predicting the risk of mortality and specific causes of mortality needs to be determined.

\section{Mortality in NAFLD and MAFLD patients}

As depicted in Table 1, very few studies have explored this topic, and the data are not conclusive. Huang et al. ${ }^{[44]}$ followed up for 22 years 12,480 patients with steatosis diagnosed by US enrolled from the Third NHANES III register and investigated prevalence of NAFLD or MAFLD and their association with mortality. Despite very similar prevalence at baseline (around 27\%), MAFLD increased the risk for all-cause mortality by a greater magnitude than NAFLD ( $\mathrm{HR}=2.07,95 \% \mathrm{CI}: 1.86-2.29 v s$. $\mathrm{HR}=1.47,95 \% \mathrm{CI}: 1.20-$ 
1.79); however, the association with mortality was not confirmed after adjusting for metabolic parameters in both cases. When considering patients classified as only NAFLD or MAFLD, solely the MAFLD-only group independently increased the risk of all-cause mortality by $47 \%$ and of cancer-related mortality by $58 \%$, whereas the NAFLD-only group did not. No association with CV mortality was found, when considering patients fulfilling the criteria for NAFLD, MAFLD, or both, possibly emphasizing the impact of MAFLD on total mortality risk rather than on specific outcomes. In addition, these results highlight the role of metabolic alterations in predicting the risk of mortality. Based on the same population from the NHANES study, Nguyen et al. ${ }^{[45]}$ focused specifically on mortality outcome over a 15-year follow-up time in patients with NAFLD and/or MAFLD ( $n=2997)$, comparing the NAFLD-only group ( $8 \%$ ), the MAFLD-only group (17\%), and the NAFLD + MAFLD one (75\%). They found the highest cumulative all-cause mortality in the MAFLD-only group (26\%), followed by the NAFLD + MAFLD group (21.1\%) and the NAFLD-only group (10.6\%). Similar differences were found with respect to CV-related mortality (log rank test $P=0.002$ ) but not for cancer-related mortality (log rank test $P=0.2$ ). Moreover, MAFLD-only status was independently associated with a higher risk of all-cause mortality ( $\mathrm{HR}=2.4$; $95 \% \mathrm{CI}: 1.2-4.6)$ compared with the NAFLDonly one. In MAFLD patients, the risk of mortality was associated with advanced fibrosis assessed by noninvasive scores and concomitant presence of viral hepatitis.

Conversely, Semmler et al. ${ }^{[46]}$ did not find any association between MAFLD and increased mortality compared to NAFLD, identifying metabolic alterations and age as the driving factors to death. The authors analyzed 4718 Austrian patients screened for colorectal cancer and with ultrasound evidence of steatosis and divided them into different groups according to BMI and the presence of NAFLD, MAFLD, or both. Over a 7.5-year period, 278 deaths were registered, but the overall survival was comparable across all groups. When comparing MAFLD vs. non-MAFLD patients, a significantly decreased survival was observed $(P=0.021)$, however the association between MAFLD and mortality was not confirmed in multivariate analysis adjusted for age and metabolic comorbidities. This lack of association was confirmed in all groups according to BMI classes (i.e., lean, overweight, and obese).

\section{CONCLUSIONS AND OPEN QUESTIONS}

As extensively reported in the literature, both NAFLD and MAFLD are characterized by an increased burden of $\mathrm{CV}$ alteration $\mathrm{s}^{[3]}$ and mortality ${ }^{[43]}$. However, given the recent modification in nomenclature from NAFLD to MAFLD, questioning the possible changes in CV outcomes related to these conditions is mandatory.

The new inclusive term MAFLD encompasses a variety of liver disease along with hepatic steatosis which may expose patients to an increased risk of cardiovascular risk such as viral hepatitis and moderate alcohol consumption ${ }^{[8,9]}$. Therefore, an increased risk of cardiovascular complications could be expected.

In fact, despite a similar prevalence of NAFLD and MAFLD (around 30\%), some data report an increased incidence of CV events in patients affected by MAFLD but not NAFLD compared to control groups without steatosis, thus those authors concluded that the MAFLD definition identified more high-risk subjects compared to NAFLD ${ }^{[28,29]}$. Interestingly, the association between MAFLD and CV events seems related more to the burden of metabolic alterations or coexistence of viral hepatitis rather than to alcohol consumption ${ }^{[2,30]}$. This could explain to some extent the higher risk of CV alterations in MAFLD compared to NAFLD. On the other hand, some authors contrasted this evidence, but the results are observational and often obtained in small cohorts ${ }^{[30,31]}$. 
An interesting aspect emerging from the literature is that data evaluating differences in subclinical cardiovascular damage are completely missing. Only a few studies compared atherosclerotic CV scores able to predict a 10-year CV event (Framingham, Suita, ACC/ACH, etc.), between patients with NAFLD and MAFLD. The results seem orienteering towards higher CV scores in patients with MAFLD; however, the data are limited, and the use of specific population-tailored scores prevents generalization of this evidence $^{[2,411]}$.

Finally, as for mortality, MAFLD seems to increase the risk of death to a greater extent compared to NAFLD, however the burden of metabolic alterations characterizing MAFLD seems prevalent over that of steatosis itself, common to both diseases. In addition, the association with specific CV cause of death is weak $^{[45]}$.

Our review points out some relevant differences in cardiovascular risk and mortality in patients with NAFLD compared to MAFLD. However, the data in the literature are limited, often contrasting and either retrospective or retrospectively analyzed over time, so that the results cannot be considered exhaustive.

In addition, the lack of data about subclinical CV damage is a big caveat in this scenario, since understanding whether MAFLD patients present higher subclinical atherosclerotic damage or myocardial dysfunction compared to NAFLD ones could help clinicians in applying different and stricter preventive and therapeutic strategies able to prevent occurrence of CV events and death.

Therefore, despite the preliminary evidence is inclined to an increased CV risk and mortality in patients affected by MAFLD compared to NAFLD, further prospective studies are warranted to confirm this hypothesis, possibly evaluating also subclinical aspects of the CV damage and application of preventive approaches.

\section{DECLARATIONS}

\section{Authors' contributions}

Revised the literature, focusing on full text paper regarding comparison of cardiovascular disease between patients with NAFLD and MAFLD: Lombardi R, Francione P, Cinque F, Cespiati A

Wrote the draft of the manuscript: Lombardi R

Carried the critical revision of the manuscript to its final form and contributed to the review for important intellectual content: Fracanzani AL, Fargion S

\section{Availability of data and materials}

Not applicable.

\section{Financial support and sponsorship}

None.

\section{Conflicts of interest}

All authors declared that there are no conflicts of interest.

\section{Ethical approval and consent to participate}

Not applicable. 


\section{Consent for publication}

Not applicable.

\section{Copyright}

(c) The Author(s) 2021.

\section{REFERENCES}

1. Younossi ZM, Koenig AB, Abdelatif D, Fazel Y, Henry L, Wymer M. Global epidemiology of nonalcoholic fatty liver disease-Metaanalytic assessment of prevalence, incidence, and outcomes. Hepatology 2016;64:73-84. DOI PubMed

2. Serfaty L, Lemoine M. Definition and natural history of metabolic steatosis: clinical aspects of NAFLD, NASH and cirrhosis. Diabetes Metab 2008;34:634-7. DOI PubMed

3. Adams LA, Anstee QM, Tilg H, Targher G. Non-alcoholic fatty liver disease and its relationship with cardiovascular disease and other extrahepatic diseases. Gut 2017;66:1138-53. DOI PubMed

4. Fargion S, Porzio M, Fracanzani AL. Nonalcoholic fatty liver disease and vascular disease: state-of-the-art. World $J$ Gastroenterol 2014;20:13306-24. DOI PubMed PMC

5. Ekstedt M, Hagström H, Nasr P, et al. Fibrosis stage is the strongest predictor for disease-specific mortality in NAFLD after up to 33 years of follow-up. Hepatology 2015;61:1547-54. DOI PubMed

6. Golabi P, Otgonsuren M, de Avila L, Sayiner M, Rafiq N, Younossi ZM. Components of metabolic syndrome increase the risk of mortality in nonalcoholic fatty liver disease (NAFLD). Medicine (Baltimore) 2018;97:e0214. DOI PubMed PMC

7. Schaffner F, Thaler H. Nonalcoholic fatty liver disease. Prog Liver Dis 1986;8:283-98. PubMed

8. Lonardo A, Ballestri S, Guaraldi G, et al. Fatty liver is associated with an increased risk of diabetes and cardiovascular disease evidence from three different disease models: NAFLD, HCV and HIV. World J Gastroenterol 2016;22:9674-93. DOI PubMed PMC

9. Mostofsky E, Chahal HS, Mukamal KJ, Rimm EB, Mittleman MA. Alcohol and immediate risk of cardiovascular events: a systematic review and dose-response meta-analysis. Circulation 2016;133:979-87. DOI PubMed PMC

10. Eslam M, Sanyal AJ, George J; International Consensus Panel. MAFLD: a consensus-driven proposed nomenclature for metabolic associated fatty liver disease. Gastroenterology 2020;158:1999-2014.e1. DOI PubMed

11. Eslam M, Newsome PN, Sarin SK, et al. A new definition for metabolic dysfunction-associated fatty liver disease: an international expert consensus statement. J Hepatol 2020;73:202-9. DOI PubMed

12. Rastogi A, Shasthry SM, Agarwal A, et al. Non-alcoholic fatty liver disease - histological scoring systems: a large cohort single-center, evaluation study. APMIS 2017;125:962-73. DOI PubMed

13. Kim Y, Han E, Lee JS, et al. Cardiovascular risk is elevated in lean subjects with nonalcoholic fatty liver disease. Gut Liver 2021. DOI PubMed

14. Ruscica M, Corsini A, Ferri N, Banach M, Sirtori CR. Clinical approach to the inflammatory etiology of cardiovascular diseases. Pharmacol Res 2020;159:104916. DOI PubMed PMC

15. Lin S, Huang J, Wang M, et al. Comparison of MAFLD and NAFLD diagnostic criteria in real world. Liver Int 2020;40:2082-9. DOI PubMed

16. Petta S, Maida M, Macaluso FS, et al. Hepatitis C virus infection is associated with increased cardiovascular mortality: a meta-analysis of observational studies. Gastroenterology 2016;150:145-55.e4; quiz e15-6. DOI PubMed

17. Targher G. Non-alcoholic fatty liver disease, the metabolic syndrome and the risk of cardiovascular disease: the plot thickens. Diabet Med 2007;24:1-6. DOI PubMed

18. Targher G, Byrne CD, Lonardo A, Zoppini G, Barbui C. Non-alcoholic fatty liver disease and risk of incident cardiovascular disease: a meta-analysis. J Hepatol 2016;65:589-600. DOI PubMed

19. Anstee QM, Mantovani A, Tilg H, Targher G. Risk of cardiomyopathy and cardiac arrhythmias in patients with nonalcoholic fatty liver disease. Nat Rev Gastroenterol Hepatol 2018;15:425-39. DOI PubMed

20. Fracanzani AL, Burdick L, Raselli S, et al. Carotid artery intima-media thickness in nonalcoholic fatty liver disease. Am $J$ Med 2008;121:72-8. DOI PubMed

21. Fracanzani AL, Pisano G, Consonni D, et al. Epicardial adipose tissue (EAT) thickness is associated with cardiovascular and liver damage in nonalcoholic fatty liver disease. PLoS One 2016;11:e0162473. DOI PubMed PMC

22. Petta S, Argano C, Colomba D, et al. Epicardial fat, cardiac geometry and cardiac function in patients with non-alcoholic fatty liver disease: association with the severity of liver disease. J Hepatol 2015;62:928-33. DOI PubMed

23. Sinn DH, Kang D, Chang Y, et al. Non-alcoholic fatty liver disease and progression of coronary artery calcium score: a retrospective cohort study. Gut 2017;66:323-9. DOI PubMed

24. Bonacini M, Kassamali F, Kari S, Lopez Barrera N, Kohla M. Racial differences in prevalence and severity of non-alcoholic fatty liver disease. World J Hepatol 2021;13:763-73. DOI PubMed PMC

25. Zeb I, Li D, Budoff MJ, et al. Nonalcoholic fatty liver disease and incident cardiac events: the multi-ethnic study of atherosclerosis. $J$ Am Coll Cardiol 2016;67:1965-6. DOI PubMed

26. Oni E, Budoff MJ, Zeb I, et al. Nonalcoholic fatty liver disease is associated with arterial distensibility and carotid intima-media thickness: (from the Multi-Ethnic Study of Atherosclerosis). Am J Cardiol 2019;124:534-8. DOI PubMed

27. Al Rifai M, Silverman MG, Nasir K, et al. The association of nonalcoholic fatty liver disease, obesity, and metabolic syndrome, with 
systemic inflammation and subclinical atherosclerosis: the Multi-Ethnic Study of Atherosclerosis (MESA). Atherosclerosis 2015;239:629-33. DOI PubMed PMC

28. Niriella MA, Ediriweera DS, Kasturiratne A, et al. Outcomes of NAFLD and MAFLD: results from a community-based, prospective cohort study. PLoS One 2021;16:e245762. DOI PubMed PMC

29. Lee H, Lee YH, Kim SU, Kim HC. Metabolic dysfunction-associated fatty liver disease and incident cardiovascular disease risk: a nationwide cohort study. Clin Gastroenterol Hepatol 2021;19:2138-2147.e10. DOI PubMed

30. Guerreiro GTS, Longo L, Fonseca MA, de Souza VEG, Álvares-da-Silva MR. Does the risk of cardiovascular events differ between biopsy-proven NAFLD and MAFLD? Hepatol Int 2021;15:380-91. DOI PubMed

31. Zhang HJ, Wang YY, Chen C, Lu YL, Wang NJ. Cardiovascular and renal burdens of metabolic associated fatty liver disease from serial US national surveys, 1999-2016. Chin Med J (Engl) 2021;134:1593-601. DOI PubMed PMC

32. Greenland P, Knoll MD, Stamler J, et al. Major risk factors as antecedents of fatal and nonfatal coronary heart disease events. JAMA 2003;290:891-7. DOI PubMed

33. Wilson PW, D'Agostino RB, Levy D, Belanger AM, Silbershatz H, Kannel WB. Prediction of coronary heart disease using risk factor categories. Circulation 1998;97:1837-47. DOI PubMed

34. D'Agostino RB Sr, Vasan RS, Pencina MJ, et al. General cardiovascular risk profile for use in primary care: the Framingham Heart Study. Circulation 2008;117:743-53. DOI PubMed

35. Treeprasertsuk S, Leverage S, Adams LA, Lindor KD, St Sauver J, Angulo P. The Framingham risk score and heart disease in nonalcoholic fatty liver disease. Liver Int 2012;32:945-50. DOI PubMed PMC

36. Conroy R. Estimation of ten-year risk of fatal cardiovascular disease in Europe: the SCORE project. Eur Heart J 2003;24:987-1003. DOI PubMed

37. Goff DC Jr, Lloyd-Jones DM, Bennett G, et al. 2013 ACC/AHA guideline on the assessment of cardiovascular risk: a report of the American College of Cardiology/American Heart Association Task Force on Practice Guidelines. J Am Coll Cardiol 2014;63:2935-59. DOI PubMed PMC

38. Motamed N, Rabiee B, Poustchi H, et al. Non-alcoholic fatty liver disease (NAFLD) and 10-year risk of cardiovascular diseases. Clin Res Hepatol Gastroenterol 2017;41:31-8. DOI PubMed

39. Nishimura K, Okamura T, Watanabe M, et al. Predicting coronary heart disease using risk factor categories for a Japanese urban population, and comparison with the framingham risk score: the suita study. J Atheroscler Thromb 2014;21:784-98. DOI PubMed

40. Jung KJ, Jang Y, Oh DJ, et al. The ACC/AHA 2013 pooled cohort equations compared to a Korean Risk Prediction Model for atherosclerotic cardiovascular disease. Atherosclerosis 2015;242:367-75. DOI PubMed

41. Tsutsumi T, Eslam M, Kawaguchi T, et al. MAFLD better predicts the progression of atherosclerotic cardiovascular risk than NAFLD: Generalized estimating equation approach. Hepatol Res 2021;51:1115-28. DOI PubMed

42. Simon TG, Roelstraete B, Khalili H, Hagström H, Ludvigsson JF. Mortality in biopsy-confirmed nonalcoholic fatty liver disease: results from a nationwide cohort. Gut 2021;70:1375-82. DOI PubMed PMC

43. Liu Y, Zhong GC, Tan HY, Hao FB, Hu JJ. Nonalcoholic fatty liver disease and mortality from all causes, cardiovascular disease, and cancer: a meta-analysis. Sci Rep 2019;9:11124. DOI PubMed PMC

44. Huang Q, Zou X, Wen X, Zhou X, Ji L. NAFLD or MAFLD: which has closer association with all-cause and cause-specific mortality? Front Med (Lausanne) 2021;8:693507. DOI PubMed PMC

45. Nguyen VH, Le MH, Cheung RC, Nguyen MH. Differential clinical characteristics and mortality outcomes in persons with NAFLD and/or MAFLD. Clin Gastroenterol Hepatol 2021;19:2172-81.e6. DOI PubMed

46. Semmler G, Wernly S, Bachmayer S, et al. Metabolic Dysfunction-Associated Fatty Liver Disease (MAFLD)-rather a bystander than a driver of mortality. J Clin Endocrinol Metab 2021;106:2670-7. DOI PubMed 